\title{
Design of a Remote Maintenance System for ABB Drives
}

\author{
Wei Liu \\ Master degree candidate School of Information Engineering, Beijing Institute of Fashion Technology, Beijing, China \\ Yanping Wang \\ Corresponding author School of Information Engineering, Beijing Institute of Fashion Technology, Beijing, China
}

\begin{abstract}
ABB Drives is a highly technical product which has been widely used in metallurgical, mining, windmill farm, building automation, drilling rig and oilfield. This also presents many characteristics such as large number of servicing points plus a wide geographic spread. Since most of them are located at less accessible areas of the world, the importance of rapid diagnosis and maintenance technology is obvious which ensure the security and reliability of the drive system becomes very important. Remote maintenance system is a service that supported by computer technology, communication technology, network and multimedia technology to provide a safe, efficient and convenient way to maintain the product remotely. This paper focuses on how to build a maintenance system for ABB Drives that integrating remote monitoring, control and diagnose all together.
\end{abstract}

KEYWORD: Remote system; Remote maintenance; PLC; DTU

\section{INTRODUCTION}

This papermainly introduces the development background, design scheme and component selection. The design of hardware is mainly about configuration for DTU, PLC and ABB drives unit. The DTU is connected with PLC via RS485, PLC and the drives is connected via RS485 and MODBUS to from a group control system. In software part is the coding of host server, programming of PLC and WEB interface design for mobile devices.

The host server software is developed by FAMEVIEW configuration software to realize realtime remote data access, malfunction alarm, control and historical data retrieve. The PLC is programmed by ABB's CoDeSys software to establish communication between $\mathrm{ABB}$ drives to realize the functions of access, control and setting target parameters.

\section{THE OVERALL SCHEME}

DTU and transmission equipmentthrough the Modbus communication, the DTU collected data is transmitted through the Internet to the data serve, DTU data server can also control transmission equipment.
When more than one site transmission equipment, or the transmission device does not support the Modbus communication and some special projects, We need monitor the equipment's operating environment temperature and humidity at any times, or each state of the control circuit, By adding a PLC system needs this parameter unified collection, then, DTU sent it to the Data Center。

On the data server to develop a PC software, It is used to collect the data transmitted by the DTU, and posted online by the built-in WEB publishing capabilities, The main achievement (Figure 1):

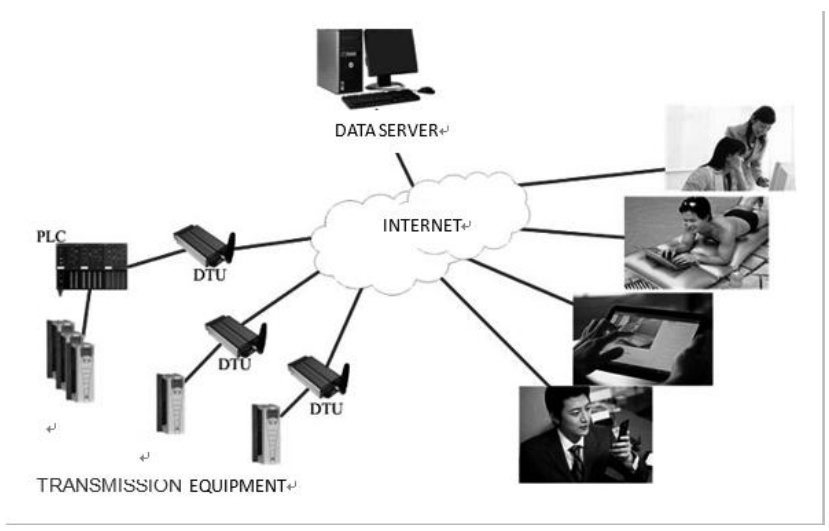

Figure 1 the overall scheme

a. Equipment maintenance personnel can monitor the Internet for the transmission equipment via computer. 
b. The users can monitor it on the smartphone remotely. Due to the PC software for Web publishing features are not supported by the mobile browsers, in order to achieve this functionality. This requires the data server, based on using the VB language, to extract the data from the PC software, and developed an ASP system and publish it out.

c. In the data server upload an SMS module, it is used to send an alarm SMS.

\section{HARDWARE DESIGN}

\subsection{JY-DTU-G device communication with $A B B$ drives}

$\mathrm{ABB}$ drives remote maintenance system, the inverter parameters currently be collected includes: temperature, current, torque, frequency, motor voltage, DC voltage and fault codes. These are important parameters when the drive is running. Monitor these parameters, could help us understand the operational status of the inverter, it can forecast and diagnose the faults timely.

DTU, it's a radio terminal apparatus, which for converting serial data to IP data or IP data is converted to serial data, its data can be transmitted via the wireless communication network.

DTU hardware includes the CPU control modules, wireless communication module and power module parts. The advantage contains :Network quickly and flexible, short construction period, low cost; A wide range of network coverage; Good safety and security performance; Link supports always online, according to traffic accounting, low user cost. Shown in the Figure 2:

In Figure 2, connect the 3, 4 terminal of the DTU and the 29, 30 terminal of the inverter together, connect the 3,4 terminal of the DTU with the 10,11 terminal of the inverter. And in Figure 3, put the 2, 3 terminal of the DTU and the 29, 30 terminal of the inverter together, switching power supply for the PLC.[5]
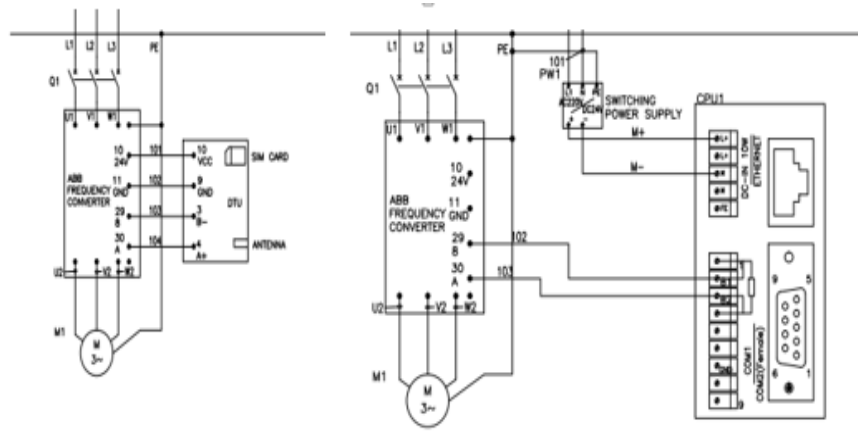

Figure2 hardware design1

\subsection{SMS module and the PLC AC500}

GSM module, Put the GSM radio frequency chips, baseband processor chips, memory, power amplifier and other devices in an integrated circuit board. It has a separate operating system, GSM RF processing, the baseband processor and provide a standard interface function module. The system uses the UniTek company's UT2355,Its products have dual-band GSM external modem; EGSM900/1800Mhz or EGSM900/1900MHz;It has authenticated by the GSM Phase2 +;The voice, SMS, fax and data transmission weredesigned for a specific application, it's an AT commands remote control system.

AC500 is a strong product in the ABB's PLC, It's can use a simple module to reach a wide range of performance levels, features and scalability function. It integrates a web server and comply with IEC 60 870-5-104 remote control protocol, it supports most industry-standard communication bus. PS501 provides a standard programming environment for the entire platform system. Shown in the Figure 3,4:

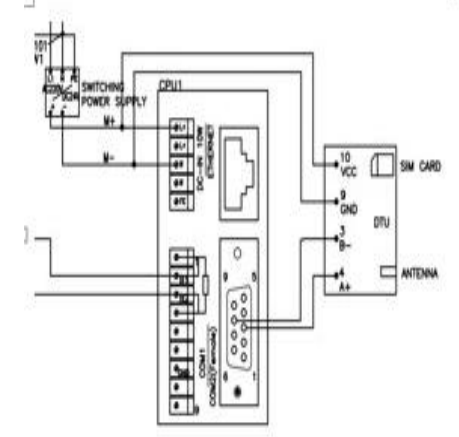

Figure 4 hardware design3

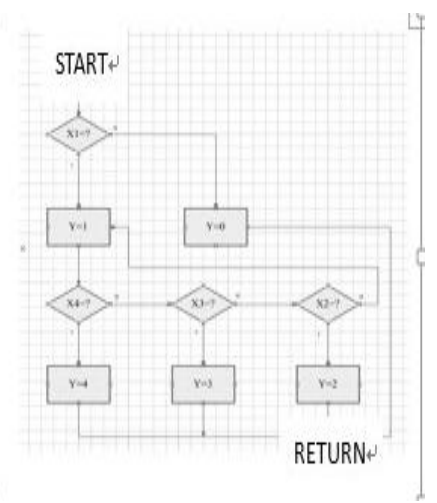

Figure 5 hardware design4

\section{SOFTWARE DESIGN}

FameView configuration software system contains a very rich set of features. According to the various functions of the $\mathrm{ABB}$ transmission equipment remote maintenance system required, Our customizable options in this system mainly contains: system settings, communications equipment, running a database, display, variable alarm, real-time reporting, recipe applications, system information, user management, global variables, variable files, groups of variables, database connectivity, batch database connections, global script, network servers, ADSL data services, SMS data services, remote connection service, OPC servers, form the recipe, Web server, real-time database connection and utilities.[1],[2]

\subsection{Establish Database}

Install the SQL database, then associate those on the Fame View configuration software, At the same time 
install the SQL Server 2000 database and be associated with the configuration software, before the database equipment to be established, first we need to install the device communication drivers. At this time, JY-DTU-G and remote maintenance system established a data communication. We use the built-in VB script writing. Program flow chart shown in Figure 5, the function of the design is $\mathrm{Y}=\mathrm{f}(\mathrm{x} 1, \mathrm{x} 2, \mathrm{x} 3, \mathrm{x} 4)$.

\subsection{Web Publishing Feature Design}

In the remote maintenance system, the computer version of the Web browser function ia under the B/S(BROWSER/SERVER) mode, use the ASP.NET language as the Client Development Language, In FAMEVIEW and embedded SQL server backend development language. Install IIS (Internet Information Server). IIS is a Web service component, Web server, FTP server, NNTP server and SMTP server are contained in it, all the aspects which are used for web browsing, file transfer, mail and other news services and so on, It makes the information published on the network (including the Internet and LAN) has become a very easy things.

\subsection{ASP Programming}

First in the main directory of the Web publishing builds two virtual directories, PcandWap, where the Pc points to the "D:|FameView $\mid$ WebPath" Path, Wappoints to the D:IWeblWap path。

Second, build a index.asp file in the main directory of Web publishing, the add the computer version and mobile version of the page select; In it, $\mathrm{PC}$ version point to the virtual directory $\mathrm{Pc}$, this page dynamic effects, and powerful, but does not support mobile browsing currently; While the mobile version point to the virtual directory Wap; All the mobile ASP system files are in the Wap virtual directory, It is mainly divided into the following pages: Login, UserMain, View, History.[3],[4]

\section{SUMMARY}

Although the basic monitoring system for remote maintenance, control and archiving function has been achieved, but the system still have some problems:

The first problem is the design of the interface is not particularly beautiful, the Web publishing interface is still very simple. The company has not yet reached the aesthetic requirements of listed products; the second problem is that although we have running simultaneously on multiple locations were tested. But with the increasing in the amount of users, the information transport system for carrying capacity requirements are also increasing, our information bearing cap on the overall system is not yet clear.

\section{ACKNOWLEDGEMENT}

Thanks teacher Wang and Su in the paper's help, to provide equipment for the thesis and collaboration, help me completed the work, and provide better suggestions.

This paper is sponsored by KYJH02140201/025 of 2014 project of Beijing science and technology

\section{REFERENCES}

[1] Popovici, Diana, Popovici, Ovidiu. A Study Regarding the Configuration of Tasks at ABB PLCs Programming. Journal of Computer Science and Control Systems, 2010, 31.

[2] JayatilakaB, SchwarzA, Hirschheim R. Determinants of ASP choice: An integrated perspective. European Journal of Information Systems, 2003, 12: 210-224.

[3] Garretson R. The ASP reincarnation. Network World, 2005, 22(34): 3436.

[4] Al William. Is ASP. Net you next Web development platform. New Architect, Mar 2002. Vol.7.

[5] Yeager Brent.How to troubleshoot your electronic scale.. Powder and Bulk Engineering. 1995. 